\title{
A Multidisciplinary Framework for Robust Planning and Decision-Making in Dynamically Changing Engineering Construction Projects
}

\author{
Hajnalka Vaagen ${ }^{1}$ and Bjørnar Aas $^{2}$ \\ ${ }^{1}$ SINTEF Technology and Society, Department of Applied Economics, \\ S.P. Andersensvei 5, 7432 Trondheim, Norway \\ hajnalka.vaagen@sintef.no \\ ${ }^{2}$ Molde University College, Britveien 2, 6411 Molde, Norway \\ bjornar.aas@vissim.no
}

\begin{abstract}
This paper proposes a multidisciplinary framework for robust planning and decision-making in dynamically changing engineering construction projects. The aim is to facilitate 'optimal' levels and 'trade-offs' between the major factors affecting decision-making throughout the project phases, to manage design changes and other disturbances, and to generate the maximum possible value. Offshore shipbuilding case analysis is applied to refine the model and to illustrate its value in decision-making.
\end{abstract}

Keywords: construction project, uncertainty, lean, decision-making, behavior.

\section{Introduction and Motivation}

One-of-a-kind specialized vessel construction is specific for European offshore shipbuilders. To achieve economic sustainability and compete with price-focused shipbuilders, combining quality with cost effective productivity and agility to meet customer changes throughout the construction process, is key. In this context, the minimization of the use of resources and the reliable adherence to a tight schedule is challenging. The dynamic dependencies, the production processes and the involved resources are complex. Frequent changes in design and legal regulations lead to continuous adjustments in planning, procurement and execution, and define the grade of uncertainty to be dealt with on a daily basis. Deviations in judgment that depart from the standards of logic and accuracy [12] may also worsen uncertainty and the process of decision-making. These characteristics trigger the need for competences, skills and tools to manage the disturbances and optimize the output.

Despite the growing number of issuant solutions, many of them ignore important characteristics of real systems; e.g. advanced design and engineering taking place concurrently with production [18]. As such, many solutions lack the flexibility necessary, and are therefore perceived to be difficult to apply in practice. Industrial stateof-the-practice shows to be largely disconnected from the theory, and is more-or-less based on intelligent rules-of-thumb [6]. And even when methods are known and do 
apply (e.g. LEAN), the success of implementation relies heavily on the human behavior [14]. Lack of trust between supply chain partners, incentive misalignment, natural risk aversion, human limitations in working memory [15] and social motivations [29] are just a few behavioral issues that can negatively impact operational success. Even the most sophisticated technology requires judgment on design and input variables. Finally, high performance teams often demonstrate unique solutions that are not visible within engineering solutions [7], and network based project organisations are not captured by existing project management literature [18]. These challenges motivate the connection of the operational element (planning \& managing tasks and resources, utilizing control functions) and the behavioral/social elements within a single framework, to facilitate robustness in decision-making and planning. Although these two elements are intertwined, the traditions in the construction industry and academic literature are to treat them separately with different focus [7].

The remaining of the paper is organized as follows. Theories to connect and relevant literature is discussed in Section 2. The proposed conceptual model for robust decision-making is presented in Section 3. Case specific applications to prove the proposed model's usefulness and a list of research paths that serve to further validate the developed framework are given in Section 4, along with the conclusion.

\section{Multidisciplinary Literature Study}

This section highlights best practice and shortcomings in different research streams discussing robust planning and decision-making in engineering construction projects. This field is mainly steered under QMS or LEAN production principles. Most advances stop, however, at the connection of classical project management theories and techniques with lean production methodologies (originally established within the context of repetitive production), and the integration of these with innovations in information technology and ERP systems to improve information availability and quality. Despite the common understanding on 'uncertainty' and 'judgment' being major elements of construction projects, it is not clear how these are treated in existing project management literature [10]. Lean theory - as a fundamental management philosophy using whatever methods and tools that fit the purpose to deliver customer requirements with no waste [4] - attempts to treat variability on a conceptual level; as opposed to Earned Value Management, a second widely applied project planning approach [8]. It is, however, unclear how this is done operationally. Recent advances, suggesting improvements and the triangulation of different methodologies exist though; see for example [8] and [13]. Lack of a structured integration of 'uncertainty' and 'judgment' into the on-going discussions, however, potentially limits the success of existing approaches. For recent behavioral discussions in operations see [11] and [6]. Flyvbjerg in [9] addresses the bias of over-optimism and the planning fallacy in risk assessment in quality control in projects. Relevant project management and planning \&control theories, their shortcomings and potential behavioral gaps - providing the motivation of this multidisciplinary approach to robust planning and decisionmaking in construction projects - are summarized by Table 1. 
Table 1. Relevant theories, their shortcomings and potential behavioral gaps

\begin{tabular}{|c|c|c|c|c|}
\hline \multicolumn{2}{|c|}{ Theory of project } & \multirow{2}{*}{$\begin{array}{l}\text { Intentions } \\
\text { Generate the maximum } \\
\text { possible amount of value }\end{array}$} & \multirow{2}{*}{$\begin{array}{l}\text { Shortcomings and possible } \\
\text { behavioral gaps } \\
\text { Lack of explicit discussion on } \\
\text { 'uncertainty' and 'judgment'; } \\
\text { Sequencing choice affected by } \\
\text { individual prejudice; } \\
\text { Concurrency in design, engineering } \\
\text { and execution is not treated }\end{array}$} & \multirow{2}{*}{$\begin{array}{l}\begin{array}{l}\text { Chosen } \\
\text { references }\end{array} \\
{[2],[4],} \\
{[10],[18]} \\
{[19,20,} \\
21],\end{array}$} \\
\hline $\begin{array}{l}\text { Theory of } \\
\text { Project } \\
\text { Management }\end{array}$ & Lean PM & & & \\
\hline & $\begin{array}{l}\text { PM under } \\
\text { uncertainty }\end{array}$ & $\begin{array}{l}\text { To explicitly reflect the } \\
\text { factual reality at all } \\
\text { project phases }\end{array}$ & $\begin{array}{l}\text { May underweight downside risk } \\
\text { aversion; }\end{array}$ & $\begin{array}{l}{[16],[22,} \\
23],[26, \\
27]\end{array}$ \\
\hline \multirow{3}{*}{$\begin{array}{l}\text { Theory of } \\
\text { project } \\
\text { planning \& } \\
\text { control }\end{array}$} & $\begin{array}{l}\text { Scheduling } \\
\text { under } \\
\text { uncertainty }\end{array}$ & $\begin{array}{l}\text { Minimize expected } \\
\text { lateness; Create flexible } \\
\text { schedules }\end{array}$ & $\begin{array}{l}\text { High complexity schedules, that are } \\
\text { not followed due to bounded } \\
\text { rationality; }\end{array}$ & $\begin{array}{l}{[17],[24]} \\
{[28]}\end{array}$ \\
\hline & $\begin{array}{l}\text { Last Planner } \\
\text { System (LPS) } \\
\text { and its } \\
\text { derivatives, } \\
\text { like Lean } \\
\text { Project } \\
\text { Planning } \\
\text { (LPP) }\end{array}$ & $\begin{array}{l}\text { Lean Construction's main } \\
\text { tool for making design } \\
\text { and construction } \\
\text { processes predictable; }\end{array}$ & $\begin{array}{l}\text { Fails to properly connect higher and } \\
\text { lower level plans; } \\
\text { Biased interpretation of the LPS } \\
\text { assignment release rules; } \\
\text { Samples are taken randomly, and } \\
\text { humans are not good randomizer; } \\
\text { Worker differences increase task } \\
\text { variability }\end{array}$ & $\begin{array}{l}{[3,4,5],} \\
{[8],[13]}\end{array}$ \\
\hline & $\begin{array}{l}\text { Earned Value } \\
\text { Management }\end{array}$ & $\begin{array}{l}\text { Maximal earned value; } \\
\text { Effective integration of } \\
\text { key aspects of a project } \\
\text { (budget control and } \\
\text { schedule) }\end{array}$ & $\begin{array}{l}\text { Assumed independence between } \\
\text { activities and cost accounts (leading } \\
\text { to subjective interpretation); } \\
\text { Earned-value priority when releasing } \\
\text { tasks - fails when time-to-market } \\
\text { and flow are critical; }\end{array}$ & $\begin{array}{l}{[8],[25],} \\
{[30]}\end{array}$ \\
\hline
\end{tabular}

\section{The Framework Proposed to Facilitate Robust Decision-Making in Dynamically Changing Construction Projects}

The framework is generated by an initial case study research for scope definition and the multidisciplinary literature study presented in Section 2. It is built around the typically critical factors that affect robustness in construction project planning and execution, and the understanding on how the behavioral element is affecting these throughout the project phases. The following example from the case shipbuilder attempts to indicate the major aspects to be captured by a multidisciplinary framework: Extensive grade of tacit knowledge and collaboration networks "built on trust" impact strategic decisions on the design flexibility offered to the customers during the construction process. Flexibility in design is, then, affecting tactical level engineering\& production planning decisions. Flexibility in project scheduling in offshore shipbuilding potentially means modeling hundreds of activities, complex dependency patterns and a large number of activities with uncertainty; schedules that are difficult to follow due to bounded rationality (even when we disregard the complexity of developing 
such plans). The state-of-practice is more like judgmental adjustments of deterministic solutions provided by some standard software. Such multilevel interactions, involving both automated and judgmental processes, trigger the connection between the engineering and human elements. Although the importance of the human element is recognized, neither judgmental decision-making nor the discussion on the tradeoff between automated and judgmental processes throughout the project phases has so far become an integrated part of how project planning is commonly done.

Having a starting point in [1], this paper assumes the major factors affecting decision-making to be information availability and solving capability. The authors in [1] define efficient management of logistics planning as efficient resource allocation across planning ability and information gathering. The authors state that if for instance a company enters into a supply chain collaboration which dramatically improves information availability, or if the company implements new optimization software, the production possibility curve (in a microeconomic point of view) will shift. The underlying motivation for such actions is to increase the overall productivity since a state of inefficiency arises when there is a mismatch between the level of information availability and solving capability: hence resource utilization and exploitation is not optimal. The major aim of the framework is to enable the development of robust solutions, by 'understanding' and consciously facilitating optimal levels and tradeoffs of information availability and solving capability at all project phases. Information availability (IA) is defined here as objective information, factual and observable for the decision maker; such as, legal regulations, market and customer data, supplier data, production times, guidelines from the owners on the grade of risk to be taken, etc. Objective information is the same for multiple reporters, close to the universal truth, and as such, helpful for decision-making. Interpretation and judgment transforms objective into subjective information. The authors in [1] did not focus on the human element, and hence lose the differentiation between objective and subjective information. While most decision-makers know that poor quality data fed into a computer results in poor output, few question the quality of judgments when the input information is good. This belief is opposed to recent research showing that there is substantial bias in judgments [15]. Solving Capability (SC) summarizes over analytical and critical thinking skills to evaluate problems and to make decisions, creativity and lateral thinking skills, experience, competence and tacit knowledge held by the individuals, 'language' as communication strategies, the ability to form high performance teams for generating innovative solutions, organisational traditions, and the decision methods and tools (design, engineering planning methods\& tools, information technology, others).

Figure 1 illustrates the conceptual multidisciplinary model proposed, summarizing over the factors identified to affect robust planning and decision-making. To clarify, planning and decision-making are interrelated, and to some extent discussed interchangeably, but with some distinction. Decisions can be made without planning, but planning cannot be done without decision-making since it is an embedded feature of planning. In an ideal setting the aim is objectively rational decision-making (in fact the correct behavior for given objective information in a given situation). However, it cannot be assumed that humans are able to 'see and interpret' the full picture of a 
problem. Compared to the task complexity the human-centered informationprocessing capacity is limited, and humans are adaptive [15] and at best subjectively rational. The goal of modeling is to bring decisions as close as possible to subjective rationality; however, models also require human decisions on design and input variables. Their appropriateness in a given situation depends on the decision-maker's knowledge and aspiration level. In summary, the impact area of the human behaviour is substantial, as highlighted by the model on Figure 1. The objective information is subject to interpretation and prediction. The interpretations and predictions are also constrained by the sophistication level of the information technology.

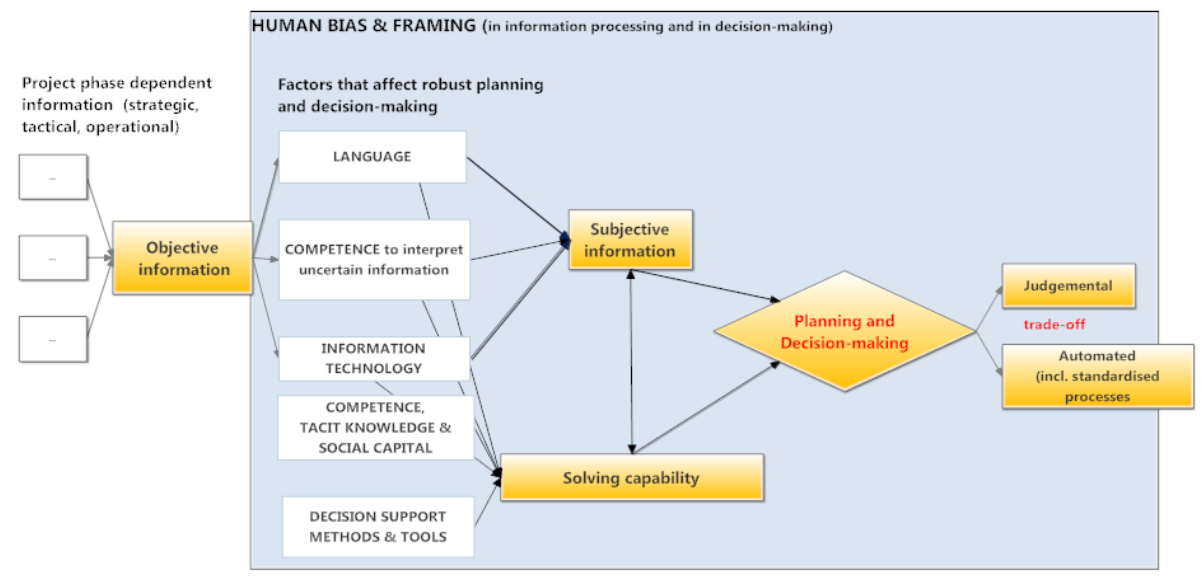

Fig. 1. Conceptual model for robust planning and decision-making

Concluding the section, developments of robust solutions can be summarized by improvements in either information availability or solving capabilities. In construction projects, decision-making \& planning differ along the project phases; as also information availability and solving capabilities differ. It is generally known that information availability is low at the start of the project, while the impact of changes is relatively low. Towards the end of the project life-cycle uncertainty reveals, but the ability to influence/change is low. If the conditions for maneuverability (i.e. flexibility) are not created on a higher level, unexpected events and variation orders potentially lead to process disturbance with high adaptation costs. Some of the answers to the challenges to be solved have embedded options on different levels of the project lifecycle (from product architecture, to engineering, planning and execution). The indepth understanding on how decisions, information and solving capability changes during the project life-cycle is, as such, crucial for the project's success; and a central message in this paper. To enable this understanding, the general framework provided by Figure1 is further developed to capture the project phase-specific aspects and the major connections across phases; not presented here due to space limitations. In the validation process, the offshore shipbuilding case allowed first to refine the model and, then, to prove the model by more-or-less known examples. A future step is to illustrate process improvements, by applying knowledge from the proposed model. 


\section{Model Discussion in Offshore Shipbuilding and Conclusion}

On a general level, the proposed framework facilitates adequate levels and trade-offs between judgmental and automated decision-making to reflect strategic orientation and competitive advantage. For example, recognizing that social capital is a critical 'asset' in enabling the competitive advantage of the case shipbuilder (i.e. design flexibility throughout the construction processes), extended focus is to be given to improving SC; by mapping the social preconditions for operational excellence to design policies that enable further success, and by integrating judgment into the decision processes (particularly in engineering and production planning, where judgmental adjustments have high impact). On the other hand, when the social capital is not critical for the competitive advantage, focus on automated decision-making is crucial.

Below we clarify how the knowledge deduced from the proposed model contributes to increased robustness in decision-making. This is done by applying shipbuilding specific examples for different uncertainty handling cases - for ex. late changes in strategic equipment specifications, like engines. Uncertainty can be risk or opportunity, and is defined by the probability of occurrence and its impact if it occurs. IA directly affects probabilities, while SC drive both impact and probability. Case 1 handles the situation where the probabilities of a particular uncertainty are changed (that is, improved IA). The probability of changes in engine specifications can be reduced by front-end loading supplier strategies, before basic design takes place; concretely, by defining the 'minimal information' needed to release a particular engineering activity. This task is judgmental, and prone to bias in data interpretation. Case 2 handles situations where the outcome of the different states is changed, by implementing actions that affect SC. The negative impact of changes in engine specifications can potentially be reduced on many levels: On a strategic level, building the vessel differently to handle different engine types (e.g. platform based architecture); on a tactical level, planning the vessel differently to enable alternative sequencing in engineering and execution (planning with and without embedded uncertainty gives structurally different solutions); in execution phase, search for the social preconditions that enable maneuverability to handle variations. Case 3 handles the situation where the decision process itself is changed, by affecting SC. Changed design and project management strategies, and explicit integration of the human element, are leading to changed decision processes. Case 4 is a special situation of Case 3, and refers to increased decision frequency; affecting both SC and IA. An extreme situation of this case is when decisions are broken down to a level where the impact of taking the wrong decision is rather low compared to the overall wealth of the company; hence, the decision-maker can take a risk neutral attitude. Such cases assume that corrective actions can be taken for the next decision period. The Last Planner System in [3], implemented in the context of a shipbuilder, can be seen as a case utilizing this opportunity. The danger of maneuvering in the wrong direction (often systematically) still exists, however.

Concluding the paper, in-depth understanding of how information availability and solving capabilities change during the project life-cycle, what are the 'optimal' levels and trade-offs between these, and how the human and social elements affect these, is 
crucial for a project's success. The proposed framework facilitates the development of this understanding to enable robustness in decision-making. The following ongoing research activities, within the context of the case shipbuilder, aim to illustrate process improvements by applying the proposed model: (i)Uncertainty planning in Lean Construction; (ii)Organisational network and behavioral studies to identify how social capital and micro level behaviour (like motivation, trust, risk attitudes, cognitive overloading) influences solving capabilities and macro-level decision-making; and (iii)Cognitive bias in project planning; (iv)Front-end-loading supplier strategies.

Acknowledgements. This paper is part of the competence building research project NextShip, under Norwegian Research Council grant agreement 216418/O70. The authors thank Jan Emblemsvåg, Senior Vice President Innovation and Process Management VARD, for valuable discussions.

\section{References}

1. Aas, B., Wallace, S.W.: Management of Logistics Planning. International Journal of Information Systems and Supply Chain Management 3(3), 1-17 (2010)

2. Ballard, G., Howell, G.A.: Lean project management. Building Research \& Information 31(2), 119-133 (2003)

3. Ballard, G., Howell, G.: Last Planner Update. In: Proceedings of the 12th Annual Conference on Lean Construction, Elsinore, Denmark (2004)

4. Ballard, G., Kim, Y.W., Jang, J.W., Liu, M.: Road Map for Lean Implementation at the Project Level, Research Report 234-11, Construction Industry Institute, The University of Texas at Austin, Texas, USA, 426 (2007)

5. Ballard, G., Hammond, J., Nickerson, R.: Production Control Principles. In: Proceedings of the 17th Annual Conference of the International Group for Lean Construction, Taipei, Taiwan, pp. 489-500 (2009)

6. Bendoly, E., Donohue, K., Schultz, K.L.: Behavior in operations management: Assessing recent findings and revisiting old assumptions. Journal of Operations Management 24(6), 737-752 (2006)

7. Chinowsky, P., Diekmann, J., Galotti, V.: Social network model of construction. Journal of Construction Engineering and Management 134(10), 804-812 (2008)

8. Emblemsvåg, J.: Lean Project Planning in Shipbuilding. Journal of Ship Production and Design 30(2), 79-88 (2014)

9. Flyvbjerg, B.: Quality control and due diligence in project management: Getting decisions right by taking the outside view. International Journal f Project Management 31, 760-774 (2013)

10. Freeman, C., Seppänen, O.: Social Aspects Related to LBMS Implementation - A Case Study. In: Proceedings of the 22th Annual Conference of the International Group for Lean Construction, Oslo, Norway, p. 677 (2014)

11. Gino, F., Pisano, G.: Toward a Theory of Behavioral Operations. Manufacturing \& Service Operations Management 10(4), 676-691 (2008)

12. Haselton, M.G., Nettle, D., Andrews, P.W.: The evolution of cognitive bias. In: Buss, D.M. (ed.) The Handbook of Evolutionary Psychology: Hoboken, pp. 724-746. John Wiley \& Sons Inc., NJ (2005) 
13. Hamzeh, F.R., Ballard, G., Tommelein, I.D.: Rethinking Lookahead Planning to Optimize Construction Workflow. Lean Construction Journal, Paper 2, 15-34 (2012)

14. Halse, L., Kjersem, K., Emblemsvåg, J.: Lean Project Planning in shipbuilding: Theimplementation challenge. Paper read at 21st EurOMA Conference, Palermo, June 20-25 (2014)

15. Hogarth, R.: Judgment and Choice: The Psychology of Decision, 2nd edn. John Wiley \& Sons, Ltd., Chichester (1991)

16. Husby, O., Kilde, S., Klakegg, O.J., Torp, O., Berntsen, S.R., Samset, K.: Styringavusikkerhetiprosjekter. Rapportnr: NTNU 99006. Produksjonog Lay-out Vestfjorden AS (1999)

17. King, A., Wallace, S.W.: Modelling using stochastic programming, 173 p. Springer, Berlin (2012) ISBN: 0387878165

18. Kjersem, K., Emblemsvåg, J.: Literature review on Planning Design and Engineering Activities in Shipbuilding. In: Proceedings of the 22th Annual Conference of the International Group for Lean Construction, Norway, Oslo, p. 677 (2014)

19. Koskela, L., Howell, G.: The Theory of project Management: Explanation to Novel Methods. In: Proceedings of the 10th Annual Conference of the International Group for Lean Construction, Gramado, Brazil, IGLC 10, vol. 6(8) (2002)

20. Koskela, L., Howell, G.: The Underlying Theory of Project Management is Obsolote. In: Proceedings of the PMI Research Conference, pp. 293-302 (2002)

21. Koskela, L., Howell, G., Ballard, G., Tommelein, I.: The Foundations of Lean Construction. Design and Construction: Building in Value. In: Best, R., de Valence, G. (eds.) Butterworth-Heinemann. Elsevier, Oxford (2002)

22. Pieters, D.A.: The Influence of framing on oil and gas decision making: An overlooked human bias in organizational decision making. Lionheart Publishing Inc., Marietta (2004)

23. Richards, C.W.: A Swift, Elusive Sword: What If Sun Tzu and John Boyd Did a National Defense Review, p. 88. Center for Defense Information, Washington, DC (2003)

24. Steinhauer, D., Heinemann, M.: Looking for Gold in the Virtual Shipyard Simulation as Basis for Production Development and Production Planning in Shipbuilding, Hansa, pp. 25-27 (2004)

25. Sumara, J., Goodpasture, J.: Earned Value - The Next Generation - A Practical Application for Commercial Projects. Project Management Institute 28th Annual Seminars \& Symposium. Chicago, IL, Project Management Institute, pp. 13-17 (1997)

26. Traore, Y., Rymarava, Y.: The Human Bias in Shipbuilding Decision Making - Case study STX OSV Søviknes. MSc Thesis Molde University College, Molde, Norway (2011), http://www.nb.no/idtjeneste/URN:NBN:no-bibsys_brage_20299

27. Tøssebro, A.: Error and variation order handling in shipbuilding-case study in VARD. MSc Thesis. Molde University College, Molde, Norway (2013), http://www.nb.no/idtjeneste/URN:NBN:nobibsys_brage_46144

28. Vaagen, H., Wallace, S.W.: Modeling consumer directed substitution. International Journal of Production Economics 134(2), 388-397 (2011)

29. Urda, J., Loch, C.: Social preferences and emotions as regulators of behavior in processes. Operations Management 31(1-2), 6-23 (2013)

30. Yong-Woo, K., Ballard, H.G.: Is the Earned Value Method an Enemy of Work Flow? In: Proceedings of the 8th Annual Conference of the International Group of Lean Construction, Brighton, UK, p. 10 (2000) 